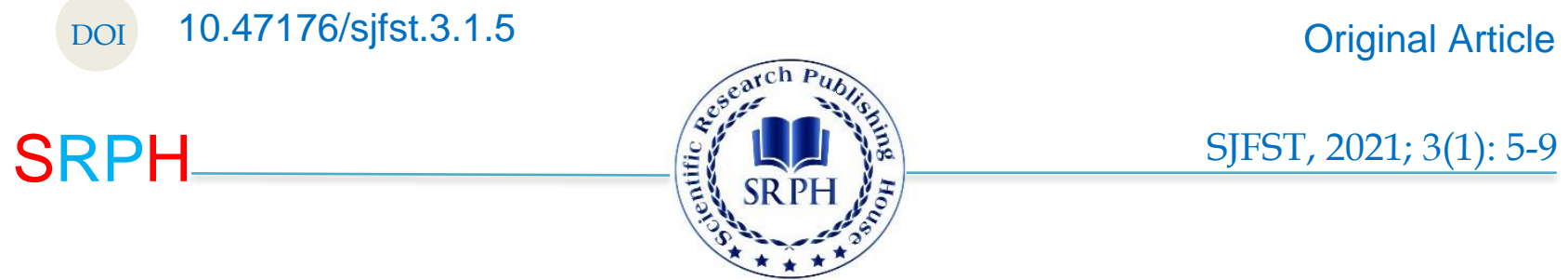

\title{
Novel Photonic Crystal Based Polycrystalline CdTe/Silicon Solar Cells
}

\author{
Mohsen Zabihi ${ }^{1}$, Hasan Sovizi ${ }^{2}$ and Saeid Marjani ${ }^{3 *}$
}

${ }^{1}$ Khorasan Electricity Distribution

Company, Mashhad, Iran.

${ }^{2.3}$ Khorasan Regional Electrical

Company, Mashhad, Iran.

\section{*Corresponding Author: \\ $\nsim$ s.marjani@krec.ir}

Received: 05 December, 2020

Accepted: 20 January, 2021

Published: 30 January, 2021

\begin{abstract}
In this paper, a novel photonic crystal $(\mathrm{PhC})$ polycrystalline $\mathrm{CdTe} /$ Silicon solar cells are theoretically explained that increase their short circuit current density and conversion efficiency. The proposed structure consist of a polycrystalline $\mathrm{CdTe} / \mathrm{Silicon}$ solar cell that a photonic crystal is formed in the upper cell. The optical confinement is achieved by means of photonic crystal that can adjust the propagation and distribution of photons in solar cells. For validation of modeling, the electrical properties of the experimentally-fabricated based CdS/CdTe solar cell is modeled and compared that there is good agreement between the modeling results and experimental results from the litterature. The results of this study showed that the solar cell efficiency is increased by about $25 \%$ compared to the reference cell by using photonic crystal. The open circuit voltage, short circuit current density, fill factor and conversion efficiency of proposed solar cell structure are $1.01 \mathrm{~V}, 40.7 \mathrm{~mA} / \mathrm{cm}^{2}, 0.95$ and $27 \%$ under global AM 1.5 conditions, respectively. Furthermore, the influence of carrier lifetime variation in the absorber layer of proposed solar cell on the electrical characteristics was theoretically considered and investigated.
\end{abstract}

Keywords: Photonic crystal (PhC), Optical confinement, CdTe/Silicon, Solar cells

\section{Introduction}

Todays, the rapid economic development leads to the speedy exponential advance of global consumption of non-renewable fossil fuels energy every year. For this reason, the countries have engrossed on clean and renewable energy sources as fossil energy alternatives. The solar energy has recognized and attracted more attention as an enormously important approach to solve the current energy crisis because of its inexhaustible, inexhaustible, pollution-free, easily accessible and copious sources. Because of excellent performances, the use of solar cells based on Cadmium Telluride (CdTe) established meaningfully. The its major specifications are direct optical bandgap close to $1.5 \mathrm{eV}$, high absorption coefficient and long term stability that seemed talented for absorbing the sun beams wavelengths of $350-850 \mathrm{~nm}$ as the solar cells. It has been shown in previous studies that the conversion efficiency of this kind of cell on the order of $20 \%$ with low energy costs [1-9].
The photonic crystal (PhC) is consist of a microstructures with periodic arrangement of two or more dielectric materials with different dielectric constants. When light propagates through a photonic crystal, the Bragg scattering occurs and photons are also modulated. The photonic forbidden band is generally separated into two types of the complete and incomplete photonic forbidden band. The complete and incomplete photonic band gaps relate to propagation of photons in all directions of photonic crystals and only in a specific direction, respectively. In addition, the photonic crystals band gap can be altered by changing the lattice parameters of photonic crystals and the dielectric constant of dielectric materials [1015].

Despite having all good performances of $\mathrm{CdS} / \mathrm{CdTe}$ solar cell, the record efficiency is still less than its predicted theoretical maximum efficiency. To enhance the performance of the solar cell further, a lot of researches are in process to improve the efficiency of CdTe solar cell. S. Marjani et al. [9] has proposed 
$21.5 \%$ and $28.5 \%$ efficient $\mathrm{CdTe} / \mathrm{Si}$ solar cell with and without the distributed Bragg reflector, including silicon dioxide/titanium dioxide $\left(\mathrm{SiO}_{2} / \mathrm{TiO}_{2}\right)$ layers at the bottom of the absorber layer. Some advance in

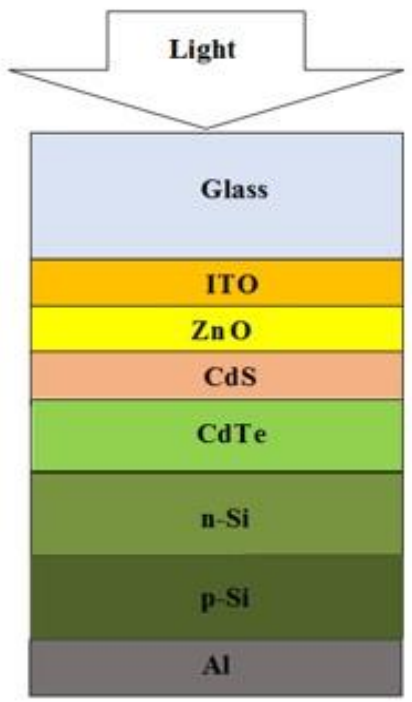

(a) photonic crystal solar cells have been reported in the literature, but polycrystalline CdTe/Silicon solar cells with photonic crystal has still to be proposed.

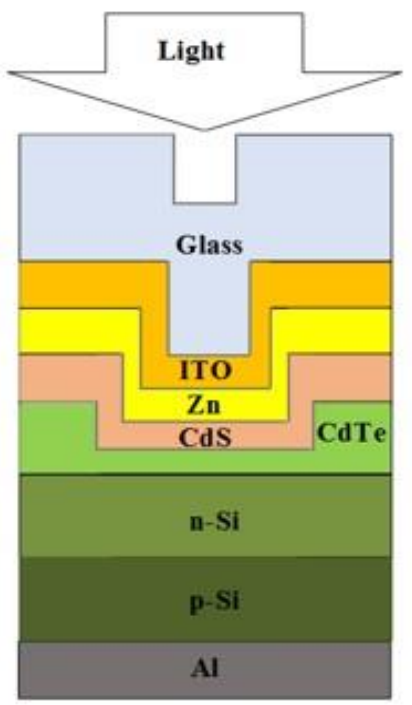

(b)

Figure 1. The cross-sectional views of (a) the previous CdS/CdTe/Si/Si multi-junction solar cell and (b) proposed photonic crystal CdTe/Si solar cell.

\section{Device Structure and Validation}

Well known SILVACO's ATLAS device simulation software [16] is used to carry out the simulation and investigate the electrical characteristics of proposed solar cell in this paper. In addition, air mass 1.5 global spectrum (AM1.5 G) with an incident irradiance of $1000 \mathrm{~W} / \mathrm{m} 2$ was assumed for all simulation. At first, the measurements reported in Ref [4] were simulated to validate the numerical models, that Table 1 compares the experimental results of open circuit voltage $\left(V_{O C}\right)$, short circuit current density (Jsc), fill factor, and cell efficiency with the simulated ones. As can be seen, Good agreement is shown between the simulation and experimental results [4]. In order to achieve further improved performance, we appraised the influence of the photonic crystal on overall solar cell conversion efficiency. Recent manuscripts of ours, which are focused on the modelling of flatted surface CdS/CdTe solar cell devices, support the adopted simulation setup [1-9,17-19].

Fig. 1 shows the proposed device structure. The previous structure is consists of a $\mathrm{CdS} / \mathrm{CdTe} / \mathrm{Si} / \mathrm{Si}$ multi-junction solar cell (Fig. 1(a)). The device parameters for the simulations are similar to that mentioned in Ref. 9. The device parameters of proposed photonic crystal CdTe/Si solar cell are same as $\mathrm{CdTe} / \mathrm{Si}$ solar cell except that a photonic crystal is formed in the upper cell that can adjust the propagation and distribution of photons in cell induced by its optical confinement (Fig. 1(b)).

Table 1

The comparison between the characteristics of the simulated cell and the reference cell.

\begin{tabular}{lcc}
\hline Parameters & Reference cell [9] & Simulated cell \\
\hline $\mathrm{V}_{\mathrm{OC}}(\mathrm{mV})$ & 840 & 865 \\
$\mathrm{~J}_{\mathrm{SC}}\left(\mathrm{mA} / \mathrm{cm}^{2}\right)$ & 26.08 & 25.73 \\
Fill factor & 0.731 & 0.734 \\
Efficiency $(\%)$ & 16 & 16.3 \\
\hline
\end{tabular}

The fundamental and primary equations of interaction of optical and electrical during the solar cells operation and modeling are electrostatic potential, carrier densities, Poisson's equation, the continuity equations and transport equations. The drift current densities for carriers based on energy balance transport model can be written as [16]: 


$$
\begin{aligned}
& J_{n}^{\mathbf{u}}=q D_{n} \nabla n-q \mu_{n} n \nabla \psi+q n D_{n}^{T} T_{n} \\
& \overrightarrow{J u}_{p}=-q D_{p} \nabla p-q \mu_{p} p \nabla \psi-q p D_{p}^{T} T_{p}
\end{aligned}
$$

where $T_{\mathrm{n}}$ and $\mathrm{T}_{\mathrm{p}}$ represent the electron and hole carrier temperatures. The $\mu_{\mathrm{n}}$ and $\mu_{\mathrm{p}}$ are the electron and hole mobilities. $D_{n}$ and $D_{p}$ are the thermal diffusivities for electrons and holes.

The rate of creation of electron-hole pairs as a function of position within a solar cell is [16]:

$$
G(x)=(1-s) \int_{\lambda}(1-r(\lambda)) f(\lambda) \alpha(\lambda) e^{-\alpha x} d \lambda
$$

where $s$ is the grid-shadowing factor, $r(\lambda)$ is the reflectance, $\alpha(\lambda)$ is the absorption coefficient, and $f(\lambda)$ is the incident photon flux that is obtained by dividing the incident power density at each wavelength by the photon energy. In general, the total generation rate is the sum of generation rate from solar and re-absorbed photons produced internally by electron-hole recombination. Also, the electron-hole recombination rate is the sum of contributions from radiative and non-radiative processes. For this reason, the concentration and field dependent mobility model, Shockley-Read-Hall recombination model and SRH concentration-dependent Lifetime were considered in aorder to higher accuracy in modeling of the mobility, recombination and carrier lifetimes.

\section{Results and Discussion}

Fig. 2 shows the voltage dependent current density for proposed photonic crystal $\mathrm{CdTe} / \mathrm{Si}$ solar cell and previous $\mathrm{CdTe} / \mathrm{Si}$ solar cell under global AM 1.5 conditions, respectively. On one hand, The optical confinement is achieved by means of photonic crystal that can adjust the propagation and distribution of photons in solar cells. In other word, it has the positive impact of multiple damped optical resonances. Then, the photonic crystal membrane can support a much higher spectral density of optical resonances with increased quality factors. As a result, this leads to a higher integrated absorption. On the other hand, photonic crystal has the most developed junction area with largest catchment volume for separating newly generated carriers, it delivers the high value of short circuit current density for small carrier diffusion lengths. Also, the photonic crystal produces the largest short circuit current density since carriers are more likely to escape contact recombination and reach the junction where they become separated. As can be seen, the obtained open circuit voltage, short circuit current density, fill factor and conversion efficiency of proposed photonic crystal CdTe/Si are $1.01 \mathrm{~V}, 40.7$ $\mathrm{mA} / \mathrm{cm}^{2}, \quad 0.95$ and $27 \%$ under global AM 1.5 conditions, respectively. In comparison to previous $\mathrm{CdTe} / \mathrm{Si}$ solar cell with $21.5 \%$ efficiency, a $25 \%$ relative enhancement in the conversion efficiency value for proposed photonic crystal CdTe/Si solar cell.

Fig. 3 shows the output power for proposed photonic crystal CdTe/Si solar cell and previous CdTe/Si solar cell under global AM 1.5 conditions. As can be seen, the output power increases due to optical confinement is achieved by means of photonic crystal that can adjust the propagation and distribution of photons in solar cells.

The carrier lifetime is defined as the average time it takes for a minority carrier to recombine. The lifetime is related to the recombination rate when the number of minority carriers is less than the doping. In order to investigate whether the carrier lifetime effect was present when the carrier lifetime of CdTe increased, the performances of the proposed photonic crystal $\mathrm{CdTe} / \mathrm{Si}$ solar cell with different carrier lifetime were also examined. Except carrier lifetime, all parameters are kept as same in these simulations. Fig. 4 shows comparison of the conversion efficiency as a function of carrier lifetime of CdTe under global AM 1.5 conditions. It is evident that the carrier lifetime of CdTe has a strong effect on the conversion efficiency. Since all carriers generated in the depletion region will be physically collected at higher lifetimes, the conversion efficiency improve with increasing the carrier lifetime. The improved conversion efficiency of proposed photonic crystal CdTe/Si solar cell was about $33 \%$ under global AM 1.5 conditions.

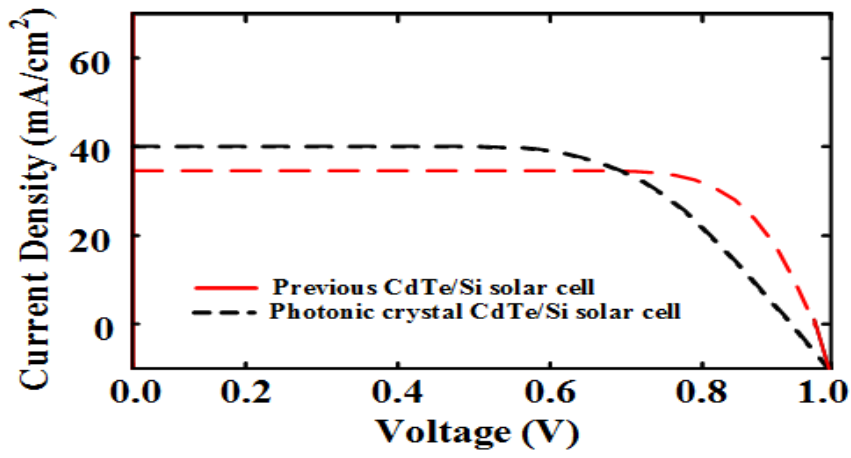

Figure 2. The voltage dependent current density for proposed photonic crystal CdTe/Si solar cell and previous $\mathrm{CdTe} / \mathrm{Si}$ solar cell under global AM 1.5 conditions. 


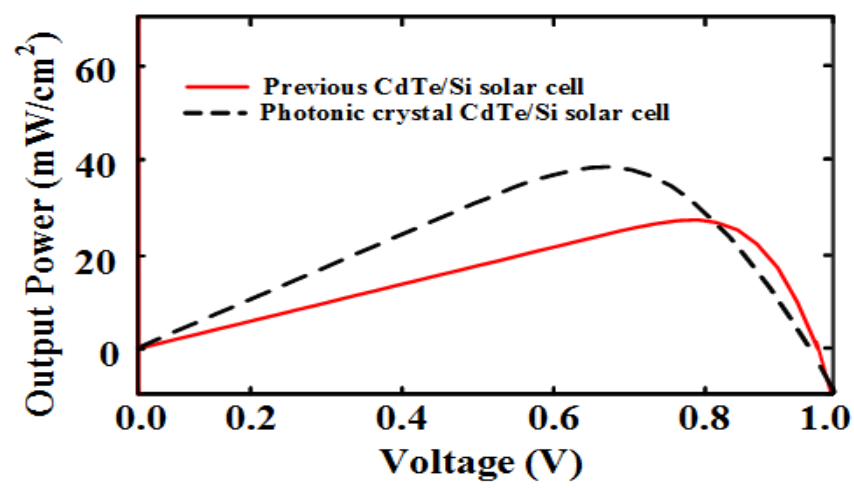

Figure 3. The voltage dependent output power for proposed photonic crystal CdTe/Si solar cell and previous $\mathrm{CdTe} / \mathrm{Si}$ solar cell under global AM 1.5 conditions.

\section{Conclusion}

A novel photonic crystal (PhC) polycrystalline $\mathrm{CdTe/Silicon} \mathrm{solar} \mathrm{cells} \mathrm{are} \mathrm{theoretically} \mathrm{explained} \mathrm{in}$ order to increase short circuit current density and conversion efficiency of cell in this paper. The proposed structure consist of a polycrystalline $\mathrm{CdTe/Silicon}$ solar cell that a photonic crystal is formed in the upper cell. The optical confinement is achieved by means of photonic crystal that can adjust the propagation and distribution of photons in solar cells. At first, the electrical properties of the experimentally-fabricated based CdS/CdTe solar cell is modeled and compared for validation of modeling that there is good agreement between the modeling results and experimental results from the litterature. The results of this study showed that the solar cell efficiency is increased by about $25 \%$ compared to the reference cell by using photonic crystal. The open circuit voltage, short circuit current density, fill factor and conversion efficiency of proposed solar cell structure are $1.01 \mathrm{~V}$, $40.7 \mathrm{~mA} / \mathrm{cm}^{2}, 0.95$ and $27 \%$ under global AM 1.5 conditions, respectively. In addition, the effect of carrier lifetime variation in the absorber layer on the electrical characteristics of proposed photonic crystal CdS/Silicon solar cell was investigated that the improved conversion efficiency was about $33 \%$ under global AM 1.5 conditions.

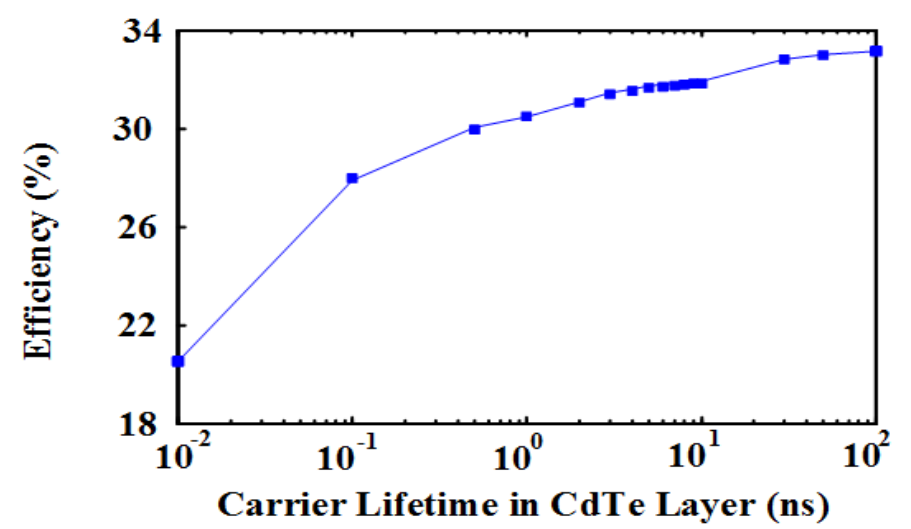

Figure 4. The comparison of the conversion efficiency as a function of carrier lifetime of CdTe for proposed photonic crystal CdTe/Si solar cell under global AM 1.5 conditions.

\section{References}

1. Marjani S, Khosroabadi S, Sabaghi M. A high efficiency ultrathin CdTe solar cell for nano-area applications. Optic Photon J. 2016; 6: 15-23.

2. Green MA, Hishikawa Y, Dunlop ED, Levi DH, Hohl-Ebinger J, Yoshita M, Ho-Baillie AWY. Solar cell efficiency tables (ver, 53). Prog Photovolt Res Appl. 2019; 27: 1-12.
3. First Solar, Press Release: First Solar Sets World Record for CdTe Solar PV Efficiency. http://investor.firstsolar.com/releasedetail.com 2018.

4. Khosroabadi S, Keshmiri SH, Marjani S. Design of a high efficiency Cds/Cdte solar cell with optimized step doping, film thickness, and carrier lifetime of the absorption layer. J Eur Optic Soc. 2014; 9: 14052-114052-6.

5. Sabaghi M, Majdabadi A, Marjani S, Khosroabadi S. 
Optimization of high-efficiency CdS/CdTe thin film solar cell using step doping grading and thickness of the absorption layer. Orient J Chem. 2015; 31: 891-896.

6. Wesoff E. Stion, Khosla-funded PV startup, hits $23.2 \%$ efficiency with tandem CIGS. 2014; http://www.greentechmedia.com/articles/read/stionkhosla-fundedpv-startup-hits-22.3-efficiency-withtandem-cigs

7. Sabaghi M, Majdabadi A, Khosroabadi S, Marjani S. A novel ultrathin CdS/CdTe solar cell with conversion efficiency of $31.2 \%$ for nano-area application. Prague, Czech Republic, Progr Electromagn Res Symp. 2015; 1152-1155.

8. Mahoodi M. Efficiency enhancement in polycrystalline $\mathrm{CdS} / \mathrm{CdTe}$ solar cell via diffraction grating and engineering absorber and back surface field layers. HOLOS. 2018; 8: 99-108.

9. Marjani S, Nasiri S, Kamel M, Sovizi H. Novel structure of polycrystalline CdS/CdTe solar cells using silicon-cell junction and distributed bragg reflector. The 34nd International Power System Conference (PSC), Tehran, Iran. 2019; 1-5.

10. Khosroabadi S, Shokouhmand A, Marjani S. Full optical 2-bit analog to digital converter based on nonlinear material and ring resonators in photonic crystal structure. Optik, 2020; 200: 163393-1-163393-7.

11. Majdabadi A, Marjani S, Sabaghi M. Threshold characteristics enhancement of a single mode $1.55 \mu \mathrm{m}$ InGaAsP photonic crystal VCSEL for optical communication systems. Optic Photon J. 2014; 4(10): 296-303.

12. Marjani S. Various elements of heat sources within an optimized photonic crystal vertical cavity surface emitting laser: Influence of hole etching depth. Asian J Chem. 2013; 25(8): 4153-4156.

13. Marjani S, Marjani H. Optimization of a long wavelength vertical-cavity surface-emitting lasers by employing photonic crystal. Asian J Chem. 2012; 24(7): 3174-3176.

14. Marjani S, Marjani $H$. Self-heating effects in a silicon carbide polymers (6H-SiC and 3C-SiC) semiconductor laser. Asian J Chem. 2012; 24(7): 31453147.

15. Marjani S, Marjani H. Effects of hole etching depth in a long wavelength InGaAsP photonic crystal vertical cavity surface emitting laser. Asian J Chem. 2012; 24(7): 3194-3196.

16. ATLAS Device Simulation Software, Silvaco Int., Santa Clara, CA, USA, 2020.

17. Mahoodi M, Marjani S, Dorostkar B. Reliability analysis model of CdS/CdTe solar cells with diffraction grating and engineering layers. The 2 nd Electrical and Computer, Conference on Innovative Researches Development (ECCIRD), Torbat-e Jam, Iran. 2019; 1 4.

18. Mahoodi M, Peiravi A, Marjani S. Time to failure analysis of polycrystalline $\mathrm{CdS} / \mathrm{CdTe} / \mathrm{InSb} / \mathrm{CdTe}$ solar cells. The 8th International Conference on Nanotechnology (ICN), Istanbul, Turkey. 2018; 1-3.

19. Mahoodi M, Marjani S. Enhanced photovoltaic performance of ultrathin polycrystalline CdS/CdTe solar cell via indium antimonide absorber layer. The 2nd International Conference on Electrical Engineering (IC-EE), Allameh Tabataba'i University, Tehran, Iran. 2017; 14.

\section{SJFST}

Copyright: (C) 2021 The Author(s); This is an open-access article distributed under the terms of the Creative Commons Attribution License (http://creativecommons.org/licenses/by/4.0), which permits unrestricted use, distribution, and reproduction in any medium, provided the original work is properly cited.

Citation: Zabihi M, Sovizi H, Marjani S. Novel Photonic Crystal Based Polycrystalline CdTe/Silicon Solar Cells. SJFST, 2021; 3(1): 5-9.

https://doi.org/10.47176/sjfst.3.1.5 